Article

\title{
Comparison of Dosimetry Protocols for Electron Beam Radiotherapy Calibrations and Measurement Uncertainties
}

\author{
Fawzia E. M. Elbashir ${ }^{1}$, Wassim Ksouri ${ }^{2}$, Mohamed Hassan Eisa ${ }^{3}$, Sitah Alanazi ${ }^{3}$, Farouk Habbani ${ }^{4}$, \\ Abdelmoneim Sulieman ${ }^{5}\left(\right.$ ) , David A. Bradley ${ }^{6,7}$ and Ibrahim I. Suliman ${ }^{3,8, *(1)}$
}

1 Department of Medical Physics, National Cancer Institute, University of Gezira, Wad Madani P.O. Box 1111, Sudan; fawzia_v@yahoo.com

2 Department of Medical Physics, Centre de Radiothérapie Hartmann 4, Rue Kleber, CS90004, CEDEX, 92309 Levallois-Perret, France; wassim.ksouri@cea.fr

3 Department of Physics, College of Science, Imam Mohammad Ibn Saud Islamic University (IMSIU), Riyadh 11642, Saudi Arabia; MHSalim@imamu.edu.sa (M.H.E.); sfenazi@imamu.edu.sa (S.A.)

4 Department of Physics, Faculty of Science, University of Khartoum, Khartoum P.O. Box 321, Sudan; habbanif@yahoo.com

5 Radiology and Medical Imaging Department, College of Applied Medical Sciences, Prince Sattam bin Abdulaziz University, Alkharj 11942, Saudi Arabia; a.sulieman@psau.edu.sa

6 Centre for Applied Physics and Radiation Technologies, School of Engineering and Technology, Sunway University, Bandar Sunway 47500, Selangor, Malaysia; d.a.bradley@surrey.ac.uk

7 Department of Physics, University of Surrey, Guildford GU2 7XH, UK

8 Radiation and Nuclear Safety Institute, Sudan Atomic Energy Commission, Khartoum P.O. Box 3001, Sudan

* Correspondence: iiidris@imamu.edu.sa; Tel.: +966-5-3891-8127

Citation: Elbashir, F.E.M.; Ksouri, W.; Eisa, M.H.; Alanazi, S.; Habbani, F.;

Sulieman, A.; Bradley, D.A.; Suliman,

I.I. Comparison of Dosimetry

Protocols for Electron Beam

Radiotherapy Calibrations and

Measurement Uncertainties. Life 2022,

12, 31. https://doi.org/10.3390/

life12010031

Academic Editors: Davide

Bianco, Filomena Loffredo

and Maria Quarto

Received: 24 November 2021

Accepted: 22 December 2021

Published: 26 December 2021

Publisher's Note: MDPI stays neutral with regard to jurisdictional claims in published maps and institutional affiliations.

Copyright: (c) 2021 by the authors. Licensee MDPI, Basel, Switzerland. This article is an open access article distributed under the terms and conditions of the Creative Commons Attribution (CC BY) license (https:// creativecommons.org/licenses/by/ $4.0 /)$.

\begin{abstract}
This paper presents guidelines for the calibration of radiation beams that were issued by the International Atomic Energy Agency (IAEA TRS 398), the American Association of Physicists in Medicine (AAPM TG 51) and the German task group (DIN 6800-2). These protocols are based on the use of an ionization chamber calibrated in terms of absorbed dose to water in a standard laboratory's reference quality beam, where the previous protocols were based on air kerma standards. This study aims to determine uncertainties in dosimetry for electron beam radiotherapy using internationally established high-energy radiotherapy beam calibration standards. Methods: $\mathrm{D}_{\mathrm{w}}$ was determined in 6-, 12- and $18 \mathrm{MeV}$ electron energies under reference conditions using three cylindrical and two planeparallel ion chambers in concert with the IAEA TRS 398, AAPM TG 51 and DIN 6800-2 absorbed dose protocols. From mean measured $D_{w}$ values, the ratio TRS 398/TG 51 was found to vary between 0.988 and 1.004, while for the counterpart TRS 398/DIN 6800-2 and TG 51/DIN 6800-2, the variation ranges were $0.991-1.003$ and $0.997-1.005$, respectively. For the cylindrical chambers, the relative combined uncertainty $(k=1)$ in absorbed dose measurements was $1.44 \%$, while for the plane-parallel chambers, it ranged from 1.53 to $1.88 \%$. Conclusions: A high degree of consistency was demonstrated among the three protocols. It is suggested that in the use of the presently determined dose conversion factors across the three protocols, dose intercomparisons can be facilitated between radiotherapy centres.
\end{abstract}

Keywords: radiation dosimetry; radiotherapy; medical LINAC; ionisation chamber; absorbed dose standards

\section{Introduction}

Current dosimetry protocols for calibration of clinical high-energy photon beams are based on the standard adoption of absorbed dose to water $\left(D_{w}\right)$ [1-4]. Absorbed dose standards allow the use of a more straightforward formalism, providing fewer uncertainties compared to the previous air kerma protocols and a more robust system of primary standards for radiation measurements $[5,6]$. In dosimetry, there is a regular need to reflect upon progress made in seeking improved accuracy, high-precision radiotherapy dosimetry, an important part of which is the comparison of the different protocols that are widely 
adopted. Overall, the desire is to reduce discrepancies in measurements and to assist in dose standardization.

Following publication of these protocols some 20 years ago, a number of studies have sought to determine differences that might derive from their adoption and to provide insights into the origin of any such differences. Several studies have been conducted to compare dosimetry protocols and address the issue reducing uncertainties in external beam therapy [7-9].

In this study, we compared the use of three widely adopted internationally authoritative protocols, namely IAEA 398, DIN 6800-2 and the American Association of Physicists in Medicine (AAPM TG 51). We add to such efforts, making measurements through use of five ionization chamber types, all acknowledged to be suitable for electron dosimetry. These comprise three cylindrical and two plane-parallel chambers, and there is the additional possibility of clinical significance from chamber-to-chamber variations in dose determination.

TG 51 is a popular protocol in North America, DIN 6800-2 enjoys a greater presence in Europe and IAEA TRS 398 enjoys more global coverage; preference for a given code is almost certainly influenced by cultural factors, prior training, habit and familiarity. With such ad hoc choice of protocol, there is a need to provide dose conversion coefficients, sufficient to facilitate intercomparison of dosimetric measurements among radiotherapy centres.

Several studies have compared the current absorbed dose standard to its predecessors, which were based on air kerma standards. Among current absorbed dose standards, studies have examined the effect of theoretical formulations on measurement results of absorbed dose to water. However, studies comparing the uncertainties arising from the measurement of absorbed dose using the current protocols are lacking.

\subsection{Basic Dosimetry Formalism}

According to IAEA TRS 398, the absorbed dose to water, $D_{w, Q}$, in a hospital beam quality $(Q)$ is determined using an ion chamber calibrated in terms of absorbed dose to water at a cobalt-60 reference beam quality $\left(Q_{0}\right)[1]$ :

$$
D_{w, Q}=M_{Q} N_{D, w, Q_{o}} k_{Q, Q_{o}}
$$

where $k_{Q, Q_{o}}$ is the beam quality correction factor, $N_{D, w, Q_{o}}$ is the absorbed dose to water calibration factor and $M_{Q}$ is the corrected ionization chamber reading at the hospital. The beam quality correction factor $k_{Q}=k_{Q}^{\prime} k_{Q}^{\prime \prime}$, where $k_{Q}^{\prime}$ and $k_{Q}^{\prime \prime}$ are factors related to the beam quality and the ion chamber, respectively. The uncorrected dosimeter reading $M_{\text {raw }}$ is corrected to the effluence quantities according to:

$$
M_{Q}=M_{\text {raw }} k_{T P} K_{\text {elec }} k_{\text {pol }} k_{s}
$$

where $k_{T P}$ is the correction factor for the ambient pressure temperature, $K_{\text {elec }}$ the calibration factor electrometer, $k_{p o l}$ correction factor to account for change in the ion chamber polarity and $k_{S}$ correction factor to account for the ion recombination.

In the AAPM protocol TG 51, the absorbed dose to water $\left(D_{w}^{Q}\right)$ at the hospital beam quality $(\mathrm{Q})$ is determined using an ion chamber absorbed dose to water calibration factor $\left(D_{D, w}^{60 \mathrm{Co}}\right)$ at a cobalt-60 reference beam quality $\left(Q_{o}\right)[2]$ :

$$
D_{w}^{Q}=M k_{Q_{,} Q_{o}} D_{D, w}^{60 C o}
$$

where $M$ is the corrected ion chamber reading, and $k_{Q, Q_{0}}$ is the beam quality correction factor. $k_{Q}=P_{g^{r}}^{Q} \cdot k_{R_{50}}^{\prime} \cdot k_{\text {ecal }}$, where $k_{R_{50}}^{\prime}$ is the factor to convert the calibration factor to the actual radiation quality $R_{50} . P_{g r}^{Q}$ accounts for ionisation gradient in the ionisation chamber, and $k_{\text {ecal }}$ is related to the radiation quality. 
In DIN 6800-2, the absorbed dose to water at the hospital beam quality $(Q)$ is determined using an un-ion chamber calibrated in terms of $\mathrm{N}$ the absorbed dose to water calibration factor at a cobalt-60 reference beam quality $\left(Q_{0}\right)[3]$ :

$$
\mathrm{D}_{\mathrm{w}}\left(\mathrm{P}_{\text {eff }}\right)=\mathrm{KNM}
$$

$\mathrm{M}$ is the corrected reading of the ion chamber; $\mathrm{K}$ is the beam quality correction. $\left(K=k_{E^{\prime}} \cdot k_{E^{\prime \prime}}\right)$, where $k_{E^{\prime}}$ and $k_{E^{\prime \prime}}$ are factors related beam quality and the ion chamber, respectively. Table 1 . Presents summary of different annotations used in the three dosimetry protocols.

Table 1. Summary of different annotations used in the three dosimetry protocols.

\begin{tabular}{|c|c|c|c|}
\hline Factor & IAEA TRS 398 & $\begin{array}{l}\text { Annotations } \\
\text { AAPM TG } 51\end{array}$ & DIN 6800-2 \\
\hline $\begin{array}{l}\text { Reference radiation beam quality } \\
\text { (cobalt-60) }\end{array}$ & $Q_{o}$ & $60 \mathrm{Co}$ & - \\
\hline Hospital radiation beam quality & $Q$ & $Q$ & - \\
\hline absorbed dose to water & $\tilde{D_{w, Q}}$ & $\widetilde{D_{w}^{Q}}$ & $\mathrm{D}_{\mathrm{w}}\left(\mathrm{P}_{\mathrm{eff}}\right)$ \\
\hline absorbed dose to water calibration factor & $N_{D, w, Q_{o}}$ & $D_{D, w}^{60} C_{0}$ & $\mathrm{~N}$ \\
\hline beam quality correction factor & $k_{Q}$ & $k_{Q}$ & K \\
\hline the corrected ion chamber reading & $\widetilde{M}_{Q}$ & $M$ & $\mathrm{M}$ \\
\hline
\end{tabular}

\subsection{Other Correction Factors of the Ion Chamber Readings}

Ionisation chamber readings are affected by the influence quantities that differ from the condition at the reference laboratory where it was calibrated. Correction factors are needed to correct for the nonreference conditions at the hospital environment. Measurements were made according to the method described in each protocol.

For air density correction, the correction factor $\mathrm{k}$ is applied:

$$
k_{p}=\frac{(273.15+T) P_{o}}{\left(273.15+T_{o}\right) P}
$$

where $P$ and $T$ are ambient pressure, and temperature and $P_{o}$ and $T_{o}$ are the reference pressure and temperature (in this study, $101.13 \mathrm{kPa}$ and $20^{\circ} \mathrm{C}$ ).

The ion recombination correction factor accounts for incomplete collection of charges in the ionization chamber. In the TRS 398 and TG 51 dosimetry protocols, ion recombination correction factor is derived using the two-voltage technique. $k_{s}$ is set at the normal operating voltage $\mathrm{V} 1$ [1-3].

$$
k_{s}=a_{o}+a_{1}\left(\frac{M_{1}}{M_{2}}\right)+a_{2}\left(\frac{M_{1}}{M_{2}}\right)^{2}
$$

where $M_{1}$ and $M_{2}$ are charges collected using polarizing voltages V1 and V1, respectively; V1/V2 > 3; and aj are coefficients used to determine Ps. In DIN, the ion recombination correction factor is determined using the equation introduced by [3]:

$$
k_{s}=1+0.54 \frac{D_{i} d^{2}}{U} \text { for } d=2.5 \mathrm{~mm}
$$

where $D_{i}$ is the dose per pulse (mGy), $d$ is the cavity height $(\mathrm{mm})$ and $U$ is the voltage.

The effect on a chamber reading because of using opposite polarity is corrected using ion chamber polarity correction factor $k_{p o l}$ given by [1-3].

$$
k_{p o l}=\left(\frac{\left|M_{+}\right|+\left|M_{ \pm}\right|}{2 M}\right) /\left(\frac{\left|M_{+}\right|+\left|M_{ \pm}\right|}{2 M}\right)_{C_{60}} .
$$

where $M$ is the ion chamber reading obtained with the polarity used regularly, $M_{+}$and $M_{-}$are the ion chamber readings at positive and negative polarities. 


\subsection{Perturbation Factors}

The sensitivity of an ionization chamber expressed in the form of an ionization chamber calibration factor depends on the water-to-air stopping power ratio of and the overall perturbation correction factor, P [1-4].

The perturbation factor corrects any departures from the ideal Bragg-Gray condition that may occur when a nonwater-equivalent wall is placed in water. P comprises the wall correction factor, $\mathrm{P}_{\text {wall }}$; fluence correction factor, $\mathrm{P}_{\mathrm{fl}}$; central electrode correction factor, $\mathrm{Pcel}$; and gradient correction factor, Pgr. For parallel plate chambers, wall $\left(\mathrm{P}_{\text {wall }}\right)$ and the fluence perturbation $\left(\mathrm{P}_{\text {cav }}\right)$ correction factors are assumed to be unity in all dosimetry protocols.

\section{Materials and Methods}

The experimental measurements were performed at the Department of Medical Physics, Institut Curie, Paris, France. Measurements were performed for three clinical electron beams delivered by two Varian medical linear accelerator types, LINAC $2300 \mathrm{C}$ and LINAC $2100 \mathrm{C}$, having energies of 6, 12 and $18 \mathrm{MeV}$. The dose-dependent characteristics of the electron beams under study are presented in presented in Table 1 . The repetition rate of the pulsed beams was $50 \mathrm{~Hz}$, giving a dose rate of $200 \mathrm{MU} / \mathrm{min}$ for all beams, which was incident horizontally on a water phantom for measurements at reference condition specified in the relevant dosimetry protocol. A variable, stabilized high voltage supply, provided the polarizing voltage. The gantry and collimator were set at zero degrees.

\subsection{Dosimetry Equipment}

Dosimetry systems that include an ion chamber with an electrometer were manufactured and calibrated at the IBA dosimetry laboratory (IBA Dosimetry $\mathrm{GmbH}$, Schwarzenbruck, Germany), with calibration traceable to the National Metrology Institute of the Federal Republic of Germany, PTB. Experimental measurements were conducted using IAEA TRS 398, AAPM TG 51 and DIN 6800-2 dosimetry protocols, and a set of five ionization chambers consisted of FC65-G type cylindrical chamber (S/N. 1630), two cylindrical farmer type CC13 and IC15 ion chambers (S/N. 8307 and 3560) and two parallel-plate ion chambers type NACP-02. The characteristics of the ionization chambers calibration coefficients are presented in Table 2.

Table 2. Physical characteristics of plane-parallel and cylindrical ionization chambers.

\begin{tabular}{|c|c|c|c|c|c|c|c|c|}
\hline \multirow{2}{*}{ Chamber } & \multirow{2}{*}{ Type } & \multicolumn{2}{|c|}{ Entrance Window } & \multicolumn{2}{|c|}{ Cavity Wall } & \multirow{2}{*}{$\begin{array}{c}\text { Cavity } \\
\text { Volume (cc) }\end{array}$} & \multirow{2}{*}{$\begin{array}{c}\text { Waterproof } \\
\text { (Y/N) }\end{array}$} & \multirow{2}{*}{ Preference } \\
\hline & & Material & $d(\mathrm{~mm})$ & Material & Thickness (mm) & & & \\
\hline NACP-02 (A) & parallel plate & $\begin{array}{c}0.17 \mathrm{~mm} \\
\text { mylar }\end{array}$ & 7 & NA & NA & NA & no & $\begin{array}{l}\text { Absolute } \\
\text { dosimetry }\end{array}$ \\
\hline NACP-02 (B) & parallel plate & $\begin{array}{l}0.17 \mathrm{~mm} \\
\text { mylar }\end{array}$ & 7 & NA & NA & NA & no & $\begin{array}{l}\text { Absolute } \\
\text { dosimetry }\end{array}$ \\
\hline IC15 & cylindrical & NA & NA & C552 & 0.4 & 0.13 & yes & $\begin{array}{l}\text { Relative } \\
\text { dosimetry }\end{array}$ \\
\hline CC13 & cylindrical & NA & NA & C552 & 0.4 & 0.13 & yes & $\begin{array}{l}\text { Relative } \\
\text { dosimetry }\end{array}$ \\
\hline FC65-G & cylindrical & NA & NA & Graphite & 0.4 & 0.65 & yes & $\begin{array}{l}\text { Absolute } \\
\text { dosimetry }\end{array}$ \\
\hline
\end{tabular}

For dose measurements, the following electrometers were deployed: Victoreen Model 530 electrometer and Keithley Model 350 electrometer (Elimpex-Medizintechnik, Spechtgasse 32, A-2340 Modelling, Austria). All measurements were made using Wellhofer Computerized water phantom (IBA Dosimetry $\mathrm{GmbH}$, Schwarzenbruck, Germany).

\subsection{Experimental Measurements}

In dosimetry measurements, the radiation beam quality index $(Q)$ is an important parameter used to determine the energy conversion factor; $k_{Q}$ required us to calculate the absorbed dose to water, as shown in Equations (1)-(3). 
Plane-parallel chambers are the recommended ion chambers for absorbed dose measurement in radiotherapy using electron beams. NACP-02 plane-parallel chambers were cross-calibrated against the FC65-G type cylindrical reference chamber at each hospital beam energy before experimental measurements, as recommended [1,2].

The reference point for the plane-parallel chamber is on the inner surface of the entrance window at its centre, and for the cylindrical chamber, it is on the chamber axis at the centre of the chamber cavity volume [1-3]. Cylindrical chambers with Cobal-60 calibration factors were used for absorbed dose measurement in radiotherapy electron beam energies < $10 \mathrm{MeV}$ [1-4].

$\mathrm{D}_{\mathrm{w}}$ is determined at a reference depth of measurements $\left(Z_{r e f}\right)$, the value of which depends on the $50 \%$ range of absorbed dose $\left(R_{50}\right)$. In TG 50 and TRS 398, the position of the reference point of the chamber for plane-parallel chambers is at the reference depth $\left(Z_{\text {ref }}\right)$; for the cylindrical chambers, it is at the effective point of measurements, 0.5 rcyl deeper than $Z_{r e f}$. The $50 \%$ range of ionization, $I_{50}$, is measured and transformed into $R_{50}$ using the following equation:

$$
R_{50}=1.029 I_{50}-0.06
$$

Reference depth of measurement (Zref) is calculated as follows:

$$
Z_{r e f}=0.6 \cdot R_{50}-0.1(\mathrm{~cm})
$$

Typical values of $R_{50}, Z_{r e f}$, and $Z_{\max }$ used for measurements are presented in Table 3 .

Table 3. Characteristics of the electron beams used.

\begin{tabular}{ccccc}
\hline \multirow{2}{*}{$\begin{array}{c}\text { Beam Energy } \\
(\mathbf{M e V})\end{array}$} & $\boldsymbol{R}_{\mathbf{5 0}}(\mathbf{c m})$ & $\boldsymbol{Z}_{\text {ref }}(\mathbf{c m})$ & TG 51, DIN 6800-2 & TRS 398 \\
\hline 6 & 2.3 & 1.3 & 1.3 & 1.4 \\
12 & 4.9 & 2.9 & 2.8 & 3.0 \\
18 & 7.6 & 2.5 & 4.5 & 4.6 \\
\hline
\end{tabular}

The experimental setup for all-electron beams was $10 \times 10 \mathrm{~cm}^{2}$ and $100 \mathrm{~cm} \mathrm{SSD}$. The depths were set at $Z_{r e f}$ and $D_{\max }$ for all energies depending on each protocol. The gantry and collimator were set at zero degrees. Using TG 51, measurements were performed at the same reference depth of $10 \mathrm{~cm}$. For TRS 398 and DIN 6800-2, measurements were performed at the two reference depths of $5 \mathrm{~cm}$ (for $6 \mathrm{MeV}$ ) and $10 \mathrm{~cm}$ (for $20 \mathrm{MeV}$ ). All measured doses were transformed into the doses at maximum depth $\left(Z_{\max }\right)$ using the central axis percentage depth dose $(P D D)$ data, according to Equation (11).

$$
D_{w, Q}\left(Z_{\text {max }}\right)=100 \cdot D_{w, Q}\left(Z_{r e f}\right) / P D D\left(Z_{r e f}\right)
$$

\subsection{Measurement Uncertainty}

Uncertainties in measurements results are determined as standard deviations evaluated by either Type A methods based on statistical observations or Type B methods based on means other than statistical methods. The combined uncertainty of the results of the two evaluation methods is determined using error propagation. Thus, the combined uncertainty in the absorbed quantity to water calculated according to IAEA TRS 398 (Equation (1) can be expressed as follows $[10,11]$ :

$$
\frac{\mathrm{u}\left(D_{w, Q}\right)}{D_{w, Q}}=\sqrt{\left(\frac{\mathrm{u}\left(M_{Q}\right)}{M_{Q}}\right)^{2}+\left(\frac{\mathrm{u}\left(N_{D, w, Q_{o}}\right)}{N_{D, w, Q_{o}}}\right)^{2}+\left(\frac{\mathrm{u}\left(k_{Q, Q_{o}}\right)}{k_{Q, Q_{o}}}\right)^{2}}
$$


where $\frac{\mathrm{u}\left(M_{Q}\right)}{M_{Q}}, \frac{\mathrm{u}\left(N_{D, w}, Q_{0}\right)}{N_{D, w}, Q_{0}},\left(\frac{\mathrm{u}\left(k_{Q, Q_{0}}\right)}{k_{Q, Q_{0}}}\right)$ are the relative standard uncertainties in the corrected hospital measurement, absorbed dose to water calibration factor and the beam quality correction factors, respectively. The relative uncertainty $\left(\frac{\mathrm{u}\left(M_{Q}\right)}{M_{Q}}\right)$ can be written as:

$\frac{\mathrm{u}\left(M_{Q}\right)}{M_{Q}}=\sqrt{\left(\frac{\mathrm{u}\left(M_{\text {raw }}\right)}{M_{\text {raw }}}\right)^{2}+\left(\frac{\mathrm{u}\left(k_{T P}\right)}{k_{T P}}\right)^{2}+\left(\frac{\mathrm{u}\left(K_{\text {elec }}\right)}{K_{\text {elec }}}\right)^{2}+\left(\frac{\mathrm{u}\left(k_{\text {pol }}\right)}{k_{\text {pol }}}\right)^{2}+\left(\frac{\mathrm{u}\left(k_{s}\right)}{k_{s}}\right)^{2}}$

where $\frac{\mathrm{u}\left(M_{\text {raw }}\right)}{M_{\text {raw }}}, \frac{\mathrm{u}\left(k_{T P}\right)}{k_{T P}}, \frac{\mathrm{u}\left(K_{\text {elec }}\right)}{K_{\text {elec }}}, \frac{\mathrm{u}\left(k_{\text {pol }}\right)}{k_{\text {pol }}},\left(\frac{\mathrm{u}\left(k_{s}\right)}{k_{s}}\right)^{2}$ are the relative standard uncertainties for uncorrected ion chamber reading $\left(M_{w}\right)$, temperature and pressure correction factor $\left(k_{T P}\right)$, electrometer calibration factor $\left(k_{\text {elec }}\right)$, polarity correction factor $\left(k_{\text {pol }}\right)$ and ion recombination correction factor $\left(k_{s}\right)$, respectively. The measurement results' overall uncertainties were quoted as expanded uncertainty at $68 \%$ confidence level with coverage factor $(k=1)$ [12].

\section{Results}

Results are presented for the $\mathrm{D}_{\mathrm{w}}$ measured using three cylindrical and two planeparallel ion chambers in concert with absorbed dose-based protocols. To compare the three protocols, measurements were made in reference conditions given in each protocol.

Table 4 presents the beam quality correction factors and data used to determine $\mathrm{D}_{\mathrm{w}}$. Table 5 presents the polarity effect $\left(k_{\text {pol }}\right)$, ion recombination $\left(k_{s}\right)$ and temperature and pressure $\left(k_{T P}\right)$ correction factors. Correction factors for the same type of chamber (IC15/CC13) were made using a single chamber and then applying them to the other, since these chambers have the same perturbation factors [1]. For NACP chambers, the contribution of the chamber factor in $k_{Q}$ is significant, so both chambers were used for measurement.

In Table 6, the absorbed dose to water ratios is given between TRS 398, TG 51 and DIN 6800-2. From mean measured $D_{w}$, the ratio TRS 398/TG 51 was found to vary between 0.988 and 1.004, while for the counterpart TRS 398/DIN 6800-2 and TG 51/DIN 6800-2, the variation ranges were 0.991 to 1.003 and 0.997 to 1.005 , respectively.

In Figure 1a-c, ratios are presented for the $\mathrm{D}_{\mathrm{w}}$ obtained using five ion chambers in the studied electron beams. The absorbed dose measured using NACP chamber differed by about $1.5 \%$ in TRS 398 and TG 51 versus that of DIN 6800-2, while the corresponding figure obtained using the FC65-G chamber deviated by about $1.6 \%$. These values agree with the results previously reported in the literature [13-15].

Table 4. Beam quality correction factors used to calculate absorbed dose to water using the TRS 398, TG 51 and DIN 6800-2 absorbed dose-based protocols.

\begin{tabular}{|c|c|c|c|c|c|}
\hline \multirow{2}{*}{ Chamber } & \multirow{2}{*}{$\begin{array}{c}\text { Beam Energy } \\
(\mathrm{MeV})\end{array}$} & \multirow{2}{*}{$N_{D, w}^{60 C o}$} & \multicolumn{3}{|c|}{$k_{Q}$} \\
\hline & & & TRS 398 & TG -51 & DIN 6800-2 \\
\hline \multirow[t]{3}{*}{ NACP-02 (13505) } & 6 & $1.748 \times 10^{8}$ & 0.9268 & 0.9302 & 0.9293 \\
\hline & 12 & & 0.8990 & 0.9059 & 0.9023 \\
\hline & 18 & & 0.8824 & 0.8881 & 0.8845 \\
\hline \multirow[t]{3}{*}{ NACP-02 (13703) } & 6 & $1.58 \times 10^{8}$ & 0.9268 & 0.9302 & 0.9293 \\
\hline & 12 & & 0.8990 & 0.9059 & 0.9023 \\
\hline & 18 & & 0.8824 & 0.8881 & 0.8845 \\
\hline \multirow[t]{3}{*}{ IC15 } & 6 & $1.3633 \times 10^{8}$ & 0.9350 & 0.9203 & 0.9395 \\
\hline & 12 & & 0.9172 & 0.9093 & 0.9138 \\
\hline & 18 & & 0.9082 & 0.9005 & 0.9060 \\
\hline \multirow[t]{3}{*}{ FC65-G } & 6 & $4.738 \times 10^{7}$ & 0.9350 & 0.9218 & 0.9376 \\
\hline & 12 & & 0.9164 & 0.9092 & 0.9128 \\
\hline & 18 & & 0.9082 & 0.8984 & 0.9051 \\
\hline
\end{tabular}


Table 5. Polarity effect $\left(k_{\text {pol }}\right)$, ion recombination $\left(k_{s}\right)$ and temperature and pressure correction factors $\left(k_{T P}\right)$.

\begin{tabular}{|c|c|c|c|c|c|c|c|c|c|}
\hline \multirow{2}{*}{$\begin{array}{c}\text { Correction } \\
\text { Factor }\end{array}$} & \multicolumn{3}{|c|}{$6 \mathrm{MeV}$} & \multicolumn{3}{|c|}{$12 \mathrm{MeV}$} & \multicolumn{3}{|c|}{$18 \mathrm{MeV}$} \\
\hline & TRS & TG 51 & DIN 6800-2 & TRS & TG 51 & $6800-2$ & TRS & TG 51 & $6800-2$ \\
\hline \multicolumn{10}{|c|}{ NACP } \\
\hline$k_{\text {pol }}$ & 0.9994 & 0.9994 & 0.9996 & 0.9993 & 0.9993 & 0.9990 & 0.9981 & 0.9981 & 0.9989 \\
\hline$k_{s}$ & 1.0096 & 1.0099 & 1.0089 & 1.0107 & 1.0110 & 1.0028 & 1.0094 & 1.0096 & 1.0113 \\
\hline$k_{T P}$ & 1.0169 & 1.0100 & 1.0169 & 1.0169 & 1.0100 & 1.0169 & 1.0169 & 1.0100 & 1.0169 \\
\hline \multicolumn{10}{|c|}{ CC13 } \\
\hline$k_{\text {pol }}$ & 1.0025 & 0.9922 & 1.0027 & 1.0009 & 1.0008 & 1.0010 & 1.0010 & 1.0005 & 1.0010 \\
\hline$k_{S}$ & 1.0244 & 1.0365 & 1.0252 & 1.0246 & 1.0247 & 1.0255 & 1.0256 & 1.0252 & 1.0259 \\
\hline$k_{T P}$ & 1.0168 & 1.0099 & 1.0168 & 1.0168 & 1.0099 & 1.0168 & 1.0169 & 1.0099 & 1.0168 \\
\hline \multicolumn{10}{|c|}{ FC65-G } \\
\hline$k_{\text {pol }}$ & 1.0014 & 1.0013 & 1.0011 & 1.0001 & 1.0001 & 0.9999 & 1.0001 & 0.9988 & 0.9992 \\
\hline$k_{s}$ & 1.0175 & 1.0181 & 1.0182 & 1.0177 & 1.0181 & 1.0180 & 1.0184 & 1.0188 & 1.0197 \\
\hline$k_{T P}$ & 1.0291 & 1.0221 & 1.0291 & 1.0291 & 1.0221 & 1.0291 & 1.0291 & 1.0221 & 1.0291 \\
\hline
\end{tabular}

Table 6. Conversion factors for absorbed dose to water between the TRS 398, TG 51 and DIN 6800-2 dosimetry protocols using NACP-02, CC13, IC15 and FC65-G ionisation chambers.

\begin{tabular}{ccccc}
\hline Ionisation Chamber & Beam Energy & $\begin{array}{c}\text { IAEA TRS 398/ } \\
\text { AAPM TG 51 }\end{array}$ & $\begin{array}{c}\text { IAEA TRS 398/ } \\
\text { DIN 6800-2 }\end{array}$ & $\begin{array}{c}\text { AAPM TG 51/ } \\
\text { DIN 6800-2 }\end{array}$ \\
\hline \multirow{2}{*}{ NACP-02 } & 6 & 1.0021 & 1.0029 & 0.9992 \\
& 12 & 1.0037 & 1.0138 & 0.9901 \\
CC13 & 18 & 1.0162 & 0.9895 & 1.0270 \\
& 6 & 0.9866 & 1.0040 & 0.9826 \\
IC15 & 12 & 0.9885 & 0.9952 & 0.9933 \\
& 18 & 0.9886 & 0.9726 & 1.0164 \\
FC65-G & 6 & 0.9917 & 1.0126 & 0.9793 \\
& 12 & 0.9934 & 0.9987 & 0.9948 \\
& 18 & 1.0164 & 0.9963 & 1.0202 \\
& 6 & 1.0065 & 1.0020 & 1.0045 \\
\end{tabular}

Our results show a high degree of consistency with the measurement uncertainty between the IAEA TRS 398 and DIN 6800-2. The most significant uncertainties are presented for plane-parallel chambers (NACP-02). Zink and Wulff [16] reported that this is mainly ascribed to the significant uncertainties of the mean ionization energy for the graphite used in the ionization chamber design and the thickness of the chamber entrance wall. Currently obtained uncertainties are in the range 1.44-1.88\%, which is in line with uncertainties reported in the most recent IAEA publication (1.4-2.1\%) [8].

Castro et al. [17] studied the uncertainty in absorbed dose to water in calibration of high-energy radiotherapy. These authors reported uncertainty $(\mathrm{k}=1)$ in the absorbed dose to water of $1.5 \%$ for an electron beam. In another study, de Prez et al. [18] reported a combined standard uncertainty $(\mathrm{k}=1)$ for the absorbed dose to water in electron beams in the range $1.6-1.8 \%$. These values compare well with the results of the current study. 

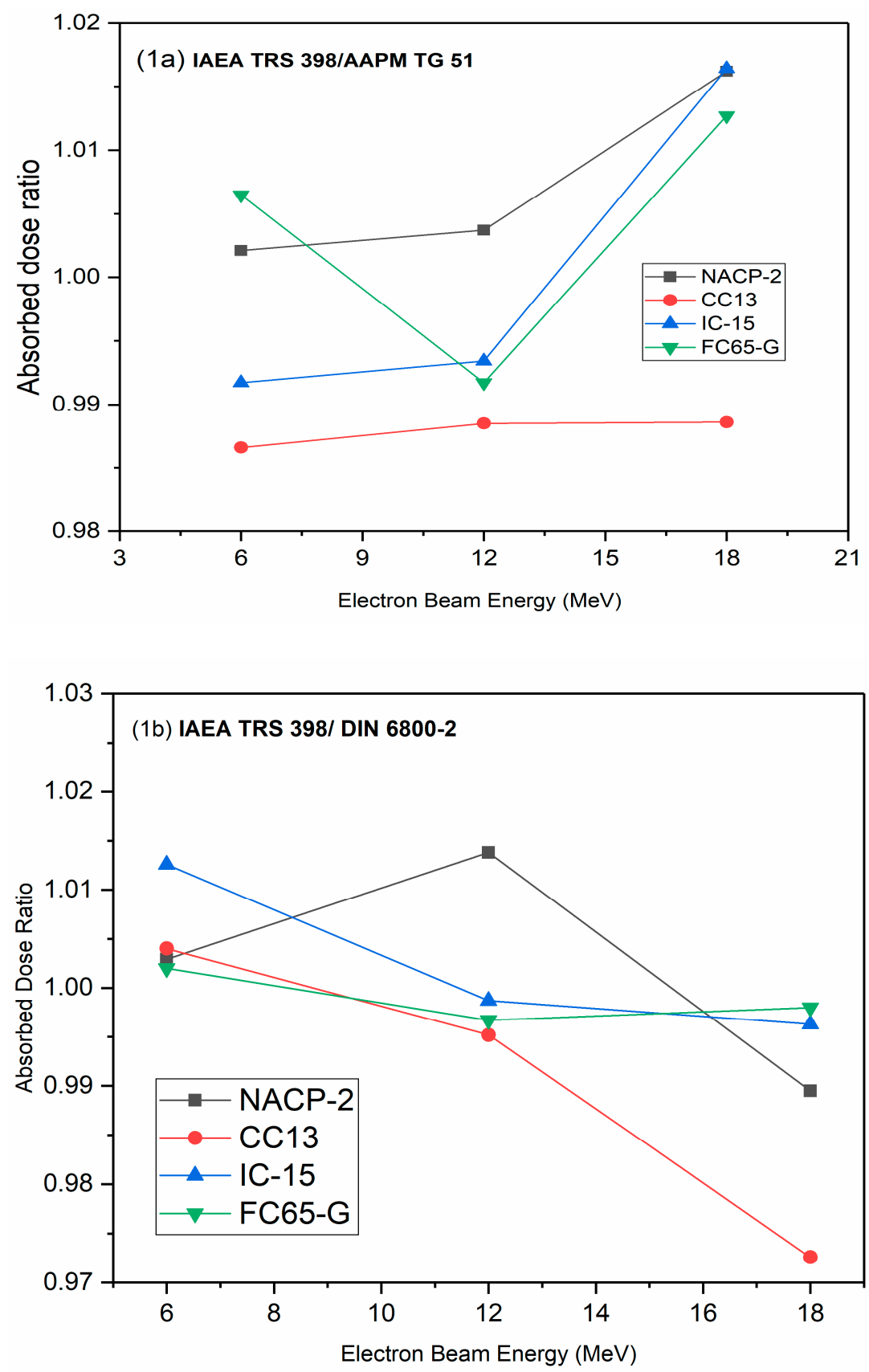

Figure 1. Cont. 


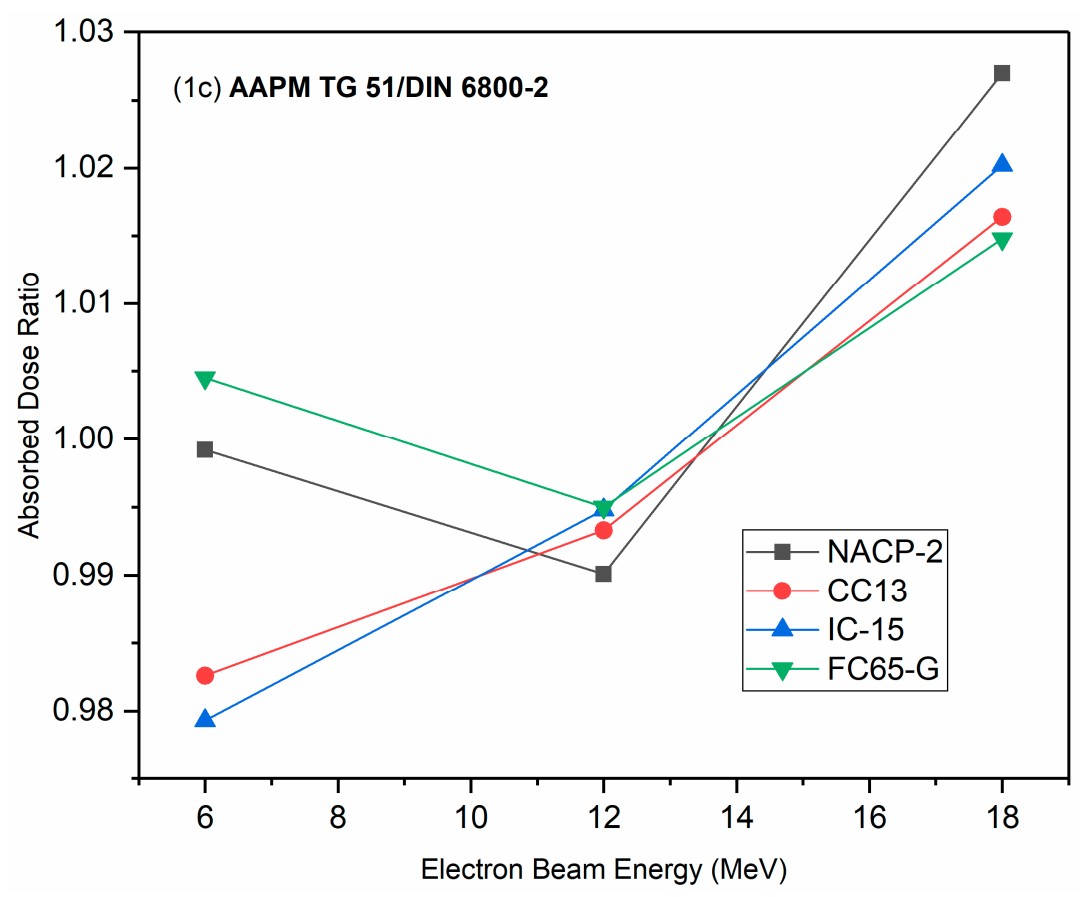

Figure 1. Ratio of the absorbed dose to water values obtained using five ionization chambers in three electron beams: (a) IAEA TRS 398/AAPM TG 51; (b) IAEA TRS 398/DIN 6800-2; (c) AAPM TG 51/DIN 6800-2.

\section{Discussion}

Absorbed dose measurements using IAEA TRS 398, AAPM TG 51 and DIN 6800-2 protocols agree within $2 \%$ for the electron beam energies under study. Different factors cause discrepancies in the measured absorbed dose values.

The results of parallel plate chambers are expected to differ from those of cylindrical chambers due to differences in the perturbation correction factors included in the radiation quality correction factors [15]. Because of this, correction factors for beam quality vary depending on the type of ionization chamber used. Another difference stems from the use of different methods to evolve influence quantities that correct for nonreference conditions. The results showed good agreement for FC65-G and the NACP-02 chambers. The discrepancy in the measurement results was up to $1.3 \%$ for the FC65-G ionization chamber. Comparing NACP chambers with TRS 398 and TG 51 to DIN 6800-2, the discrepancy in measurement results was up to $1.5 \%$, while the corresponding figure for FC65-G chambers was about $1.6 \%$ (Figure 1).

Recently, several studies were also performed to compare protocols based on absorbed dose standards. The common goal was to improve dosimetric accuracy and to report discrepancies. In conformity to our results, the agreement between the two protocols was more pronounced for NACP-02 plane-parallel chambers. A similar agreement was shown by Zakaria and Schutte, who reported a deviation up to $1.6 \%$ for the IAEA TRS 398, AAPM TG 51 and DIN 6800-2 [14].

Table 7 gives the estimated \% uncertainty (relative) in measurements of $D_{w}$, the use of high-energy electron beam clinical accelerators, and the current absorbed dose-based protocols. Concerning the required accuracy in radiotherapy, the aim is to limit the increase in toxicity to $3 \%$. Dose uncertainties $(\sigma D)$ would need to be kept to $<5 \%$ [12]. The current uncertainties fall with the stated limits. 
Table 7. Relative uncertainty (\%) associated with measurements of the absorbed dose to water, $D_{w}$, in energy electron beam radiotherapy using the IAEA TRS 398 and DIN 6800-2 dosimetry protocols.

\begin{tabular}{|c|c|c|c|c|c|c|}
\hline \multirow{2}{*}{ Influence Quantities } & & \multirow{2}{*}{ Evaluation } & \multicolumn{2}{|c|}{ Cylindrical Chamber } & \multicolumn{2}{|c|}{ Plane-Parallel Chamber } \\
\hline & & & TRS 398 & DIN 6800-2 & TRS 398 & DIN 6800-2 \\
\hline $\mathrm{ND}, \mathrm{W}$ & $\begin{array}{l}\text { Chamber } \\
\text { certificate }\end{array}$ & B & 0.55 & 0.55 & 0.55 & 0.55 \\
\hline Measurement depth & Calculated & B & 0.46 & 0.46 & 0.46 & 0.46 \\
\hline$k_{p}$ & Calculated & $\mathrm{A} / \mathrm{B}$ & 0.04 & 0.04 & 0.12 & 0.12 \\
\hline$k_{T P}^{p}$ & Calculated & $\mathrm{A} / \mathrm{B}$ & 0.01 & 0.01 & 0.01 & 0.01 \\
\hline$k_{s}$ & Calculated & $\mathrm{B}$ & 0.04 & 0.04 & 0.12 & 0.12 \\
\hline$k_{Q}$ & $\begin{array}{l}\text { IAEA } \\
\text { TRS } 398\end{array}$ & B & 1.2 & - & 1.7 & - \\
\hline$k_{E}$ & DIN 6800-2 & B & - & 1.2 & - & 1.3 \\
\hline Meter stability & $\begin{array}{l}\text { Dosimeter } \\
\text { Manual }\end{array}$ & B & 0.28 & 0.28 & 0.28 & 0.28 \\
\hline Meter reading & Calculated & A & 0.2 & 0.2 & 0.2 & 0.2 \\
\hline \multicolumn{3}{|c|}{ Combined standard uncertainty $(k=1)$} & 1.44 & 1.44 & 1.88 & 1.53 \\
\hline
\end{tabular}

\section{Conclusions}

The study found that the absorbed dose to water conversion coefficients of the three protocols were quite similar, indicating that the measurement results were very consistent. The results obtained are expected to facilitate intercomparison of measured results between hospitals using different protocols. The main sources of uncertainty in the results were chamber type and electron energy, which were attributed to differences in the perturbation factors used in the various protocols. The results reveal that a significant fraction of the uncertainties come from beam quality correction factors. These uncertainties could be reduced by having standards provide calibration of ion chambers in user beams. Results are essential for facilitating intercomparison between radiotherapy centres that use different dosimetry protocols.

Author Contributions: Conceptualization, I.I.S., F.E.M.E. and F.H.; methodology, F.E.M.E., W.K. and I.I.S.; validation, M.H.E., D.A.B., A.S. and S.A.; formal analysis, F.H., D.A.B. and S.A.; investigation, M.H.E., F.E.M.E. and S.A.; resources, I.I.S., M.H.E. and S.A.; data curation, F.E.M.E.; writing—original draft preparation, I.I.S., F.E.M.E. and W.K.; writing-review and editing, A.S., I.I.S., D.A.B. and M.H.E.; visualization, S.A., A.S. and F.H.; supervision, I.I.S. and F.H.; funding acquisition, I.I.S. and M.H.E. All authors have read and agreed to the published version of the manuscript.

Funding: The authors extend their appreciation to the Deanship of Scientific Research at Imam Mohammad Ibn Saud Islamic University for funding this work through Research Group No. RG-21-09-45.

Institutional Review Board Statement: Not applicable.

Informed Consent Statement: Not applicable.

Data Availability Statement: Data available on request.

Conflicts of Interest: The authors declare no conflict of interest.

\section{References}

1. Andreo, P.; Burns, D.T.; Hohlfeld, K.; Huq, M.S.; Kanai, T.; Laitano, F.; Smyth, V.; Vynckier, S. Absorbed Dose Determination in External Beam Radiotherapy: An International Code of Practice for Dosimetry Based on Standards of Absorbed Dose to Water; IAEA TRS 398; International Atomic Energy Agency: Vienna, Austria, 2004.

2. Almond, P.R.; Biggs, P.J.; Coursey, B.M.; Hanson, W.F.; Huq, M.S.; Nath, R.; Rogers, D.W. AAPM's TG-51 protocol for clinical reference dosimetry of high-energy photon and electron beams. Med. Phys. 1999, 26, 1847-1870. [CrossRef]

3. Deutsches Institut für Normung. Dosismessverfahren Nach der Sondenmethode für Photonen-und Elektronenstrahlung Teil 2: Ionisationsdosimetrie DIN 6800-2; Deutsches Institut für Normung: Berlin, Germany, 2008.

4. Lillicrap, S.C.; Owen, B.; Williams, J.R.; Williams, P.C. Code of practice for high-energy photon therapy dosimetry based on the NPL absorbed dose calibration service. Phys. Med. Biol. 1990, 35, 1355-1360. [CrossRef]

5. IAEA. Absorbed Dose Determination in Photon and Electron Beams; International Code of Practice, IAEA Tech. Series No.277; International Atomic Energy Agency: Vienna, Austria, 1997.

6. IAEA. The Use of Plane Parallel Ionization Chambers in High Energy Electron and Photon Beams; An International Code of Practice for Dosimetry, IAEA Tech. Series No.381; International Atomic Energy Agency: Vienna, Austria, 1997. 
7. Zakaria, A.; Schuette, W.; Younan, C. Reference Dosimetry according to the New German Protocol DIN 6800-2 and Comparison with IAEA TRS 398 and AAPM TG 51. Biomed. Imaging Interv. J. 2011, 7, e15. [PubMed]

8. Sathiyan, S.; Ravikumar, M. Absolute dose determination in high-energy electron beams: Comparison of IAEA dosimetry protocols. J. Med. Phys. Assoc. Med. Phys. India 2008, 33, 108. [CrossRef] [PubMed]

9. IAEA. Implementation of the International Code of Practice on Dosimetry in Radiotherapy (TRS 398): Review of Testing Results; IAEA TECDOC-1455; International Atomic Energy Agency: Vienna, Austria, 2005.

10. ISO. ISO/IEC GUIDE 98-3:2008 Uncertainty of Measurement_Part 3: Guide to the Expression of Uncertainty in Measurement (GUM:1995); International Organization for Standardization: Geneva, Switzerland, 2008.

11. International Atomic Energy Agency (IAEA). Measurement Uncertainty: A Practical Guide for Secondary Standards Dosimetry Laboratories; IAEA-TECDOC-1585; International Atomic Energy Agency: Vienna, Austria, 2008.

12. IAEA HH. Accuracy Requirements and Uncertainties in Radiotherapy; IAEA Human Health Series. No. 31; International Atomic Energy Agency: Vienna, Austria, 2016.

13. Al-Ahbabi, S.S.; Bradley, D.A.; Beyomi, M.; Alkatib, Z.; Adhaheri, S.; Darmaki, M.; Nisbet, A. A comparison of protocols for external beam radiotherapy beam calibrations. Appl. Radiat. Isot. 2012, 70, 1331-1336. [CrossRef] [PubMed]

14. Zakaria, G.A.; Schütte, W. Determination of absorbed dose to water for high energy photon and electron beams-Comparison of different dosimetry protocols. Z. Fur Med. Phys. 2003, 13, 281-289. [CrossRef] [PubMed]

15. Wang, Z.; Xing, S.; Wang, K.; Jin, S.; Zhang, J.; Fan, F. Direct measurement of ionization chamber absorbed dose $k_{Q}$ factors in clinical electron beams. Radiat. Meas. 2000, 139, 106481. [CrossRef]

16. Zink, K.; Wulff, J. Beam quality corrections for parallel-plate ion chambers in electron reference dosimetry. Phys. Med. Biol. 2012, 57, 1831. [CrossRef]

17. Castro, P.; García-Vicente, F.; Mínguez, C.; Floriano, A.; Sevillano, D.; Pérez, L.; Torres, J.J. Study of the uncertainty in the determination of the absorbed dose to water during external beam radiotherapy calibration. J. Appl. Clin. Med. Phys. 2008, 9, 70-86. [CrossRef] [PubMed]

18. de Prez, L.; Heukelom, S.; Jansen, B.; Jansen, W.; van de Kamer, J.; van Klink, W.; Wittkämper, F. An on-site dosimetry audit for high-energy electron beams. Phys. Imaging Radiat. Oncol. 2018, 5, 44-51. [CrossRef] [PubMed] 